\title{
The Relationship Between Pain and Psychological and Cognitive Status in Patients with Acute Low Back Pain: A Cross-Sectional Study
}

\author{
(-) Osman Ersegun Batcik, ๑ Bulent Ozdemir \\ Recep Tayyip Erdogan University Faculty of Medicine, Department of Neurosurgery, Rize, Turkey
}

\section{Abstract}

\begin{abstract}
Aim: Low back pain can lead to depression and anxiety as a result of reduced quality of life. Also, catastrophizing can aggravate the pain. Therefore, we aim to investigate the relationship between the severity of acute low back pain and the psychological states of the patients.
\end{abstract}

Methods: This cross-sectional study involved 168 patients of both genders who applied to the Neurosurgery Outpatient Clinic at the Recep Tayyip Erdogan University Training and Research Hospital between December 2020 and February 2021. Pain severity was assessed with the numerical pain rating scale (NPRS), pain catastrophizing by pain catastrophizing scale (PCS). While evaluating depression and anxiety, beck depression inventory (BDI) and beck anxiety inventory (BAI) were used, respectively.

Results: A statistically significant difference was found in the variance analysis of pain intensity and catastrophizing according to depression symptoms $(p<0.001)$. It was also observed that the difference in pain severity and catastrophizing according to anxiety symptoms was statistically significant $(p<0.001)$. There was a statistically significant correlation among the BDI, BAI, NPRS and PCS $(p<0.001)$.

Conclusion: The findings of our study showed that there is a significant relationship between anxiety, depression, and catastrophizing, and low back pain. Therefore, it is important to consider the psychological state of the patient during the treatment process.

Keywords: Low back pain, psychological state, cognitive state, pain rating, pain catastrophizing

\section{Introduction}

Low back pain is an important cause of pain, especially in developed and developing countries, and causes serious physical, psychological and economic losses (1). While $80 \%$ of people over the age of 40 experience low back pain at least once in their lives, the annual prevalence of low back pain in the society varies between 3515\% (2). According to the Turkish Statistical Institute's data evaluated in 2016; It is seen that the incidence of low back pain, lumbar hernia and other lumbar defects in society is gradually increasing and its incidence has reached $27.1 \%$ (3). The World Health Organization estimated the depression rate to be $4.4 \%$ and the anxiety disorder rate to $3.6 \%$ worldwide in 2015 (4). It is reported that these rates are higher in individuals who experience pain and whose quality of life is adversely affected (4).
In addition to being an uncomfortable condition for the person, pain can disrupt the person's quality of life and trigger anxiety and depression unless it is treated (5). Besides physical discomfort, anxiety and depression itself can also cause disability $(4,6)$. Pain tolerance and response pattern varies from person to person. While psychological factors may have an effect on this reaction, the pain itself can lead to psychological problems $(7,8)$.

In addition to depression and anxiety, patients' tendency to catastrophizing has been shown to cause pain to be perceived stronger than it actually is $(9,10)$. Catastrophizing has been defined as "thinking about the worst possible outcome of incidents and threats and increasing the likelihood of experiencing this bad outcome". Based on this definition, the pain catastrophic

Address for Correspondence: Osman Ersegun Batcik, Recep Tayyip Erdogan University Faculty of Medicine, Department of Neurosurgery, Rize, Turkey 
scale (PCS) was developed by Sullivan et al. (11) to assess the severity of personal disaster.

In our study, we aimed to investigate the relationship between the severity of pain in patients with acute low back pain and the patient's cognitive state (catastrophizing pain), and psychological state (depression and anxiety severity).

\section{Methods}

\section{Study Design}

This prospective cross-sectional study was conducted in accordance with the Declaration of Helsinki and approved by the institution's Ethics Committee (decision number: 2020/248 decision date: 23.12.2020). Proposals were made to 209 patients for the study, and 18 of 186 patients who agreed to participate in the study were excluded from the study because they did not meet the specified criteria. Therefore, the sample consisted of 168 male and female participants who applied to Recep Tayyip Erdogan University Training and Research Hospital's Neurosurgery Outpatient Clinic with the complaint of mechanical back pain between December 2020 and February 2021. Patient written informed consent was obtained after it was reported that the study would not impact patient treatment and the study protocol was announced.

History of alcohol and substance use, inability to cooperate, and disapproval of participation in the study were determined as exclusion criteria for the study. There was a total of 41 patients, including 21 who refused to participate in the study and 18 who did not meet the criteria for the study $(n=41)$.

Patients were informed about the study and those who accepted to participate in the study were directed to the service, and a neurosurgeon who has the necessary knowledge about the study subject and scales was informed about each patient's age, gender, body mass index, educational status, marital status, existing comorbidities (hypertension, diabetes mellitus), ischemic heart disease, chronic obstructive pulmonary disease, depression, anxiety etc.) have been recorded.

Pain severity was assessed using the numerical pain rating scale (NPRS) (12) and pain catastrophizing by PCS (11). The tools used to evaluate the depression and anxiety levels of the participants are the beck depression inventory (BDI) (13) and the beck anxiety inventory (BAI) (14), respectively.

\section{Numeric Rating Scale for Pain (NPRS)}

The severity of low back pain was evaluated with the Numeric Rating Scale for Pain (zero equals no pain, ten equals maximum pain). The scale is a reliable method that evaluates subjective pain intensity, does not require literacy skills, can be applied easily, and is accepted in the literature (12).

\section{Pain Catastrophizing Scale (PCS)}

Pain catastrophizing severity which was developed by Sullivan et al. (11) in 1995 using the Pain Catastrophizing Scale is used to determine the catastrophe of pain. The reliability and validity study of the Turkish version of the scale was conducted by Süren et al. (15). The scale consists of 13 questions and has three subscales: rumination, magnification and helplessness. Each question is scored between zero and four. The total score to be obtained from the scale varies between zero and 52 while high scores indicate negative results. In many countries, its validity and reliability have been studied (16).

\section{Beck Depression Inventory (BDI)}

The scale that is developed by Beck et al. (13) consists of 21 questions and the questions are scored between zero and three. The scores increasing from zero to three in this scale are proportional to the severity in the evaluated parameter. The highest score to be obtained from the scale is 63 . For the Turkish society, 17 points obtained from the $\mathrm{BDI}$ were determined as the cut-off point for moderate and severe depression. The validity and reliability of BDE in Turkish society was studied by Hisli et al. (17).

\section{Beck Anxiety Inventory (BAI)}

The 21-question scale that is developed by Beck et al. (14) assesses the severity of anxiety. Each question is scored between zero and three. The total score ranges from zero to 63. Higher scores are consistent with anxiety severity. For the Turkish society, 16 points received from the BAI have been determined as the value that distinguishes high anxiety levels. The validity and reliability of BAI in Turkish society were studied by Ulusoy et al. (18).

\section{Statistical Analysis}

The statistical analysis of the data was performed with the SPSS for Windows 22 (SPSS, IBM, Chicago, IL, USA) package program. Frequencies, percentages, means and standard deviations are given for socio-demographic variables. Data on continuous variables are given as mean standard deviation. Variables with more than two categories were analyzed by analysis of variance. When a significant difference was detected as a result of analysis of variance, the post-hoc Tukey test was applied to determine which groups the difference was due to, and Bonferroni correction was made. Pearson correlation analysis was conducted to evaluate the relationship between NPRS and PCS scores with depression and anxiety scores. In general, statistical significance was accepted as $p<0.05$ in the tests. The $p$-value $<0.05 / 6=p<0.008$ for post-hoc Tukey with Bonferroni correction was considered statistically significant. 


\section{Results}

168 patients (Female: 71, Male: 97) who met the study criteria among the patients who applied to the Recep Tayyip Erdogan University Training and Research Hospital's Neurosurgery Outpatient Clinic with the complaint of low back pain were included in the study. The mean age and standard deviation were $46.81 \pm 11.81$. The mean pain duration and standard deviation were $2.54 \pm 1.24$. Sociodemographic information is provided in Table 1. In the Lasegue test, 106 of the participants were positive (LP) and 62 of them were negative (LN). When the magnetic resonance (MR) findings were evaluated, it was seen that there were 83 people without radiological findings or bulging, 40 people with protrusion and 45 people with extrusion and sequestration (Table 2). To the findings, the pain intensity has a positive correlation of 0.60 with pain catastrophizing $(r=0.60)$, has a positive correlation with anxiety $(r=0.59)$ and has a positive correlation with depression $(r=0.60)$. There was a 0.54 positive correlation $(r=0.54)$ between pain catastrophy and anxiety, and a positive correlation $(r=0.60)$ between pain catastrophy and depressive symptoms (Table 3).

A significant difference was found between the groups (F: 26.46; $p<0.001$ ) (Table 4), when the participants were divided into four groups as minimal, mild, moderate and severe according to their depression symptoms and analysis of variance was performed in terms of their NPRS scores. Table 5 presents the results of the post-hoc test used to identify the binary group that was the source of the statistically significant difference. When these four groups were compared in terms of PCS scores, a significant difference was found between the groups ( $F$ : 31.25; $p<0.001$ ) (Table 4). The results of the post-hoc test for the relevant variance analysis are shown in Table 5.

\begin{tabular}{|l|l|}
\hline \multicolumn{2}{|l|}{ Table 1. Socio-demographic characteristics of the sample } \\
\hline \multicolumn{2}{|l|}{ ( $\%)$} \\
\hline Gender & $71(42.3)$ \\
\hline Male & $97(57.7)$ \\
\hline Marital status & \multicolumn{2}{|l|}{} \\
\hline Single & $27(16.1)$ \\
\hline Married & $141(83.9)$ \\
\hline Education & $87(51.8)$ \\
\hline Illeterate/Less than primary school & $63(37.5)$ \\
\hline Primary school & $13(97.7$ \\
\hline Middle school/High school & $5(3.0)$ \\
\hline College/University & Mean \pm Standard deviation \\
\hline \multirow{2}{*}{ Age } & $46.81 \pm 11.81$ \\
\hline
\end{tabular}

When the participants were divided into four groups as low, mild, moderate, and severe according to their anxiety symptoms, and analysis of variance in terms of NPRS scores, a significant difference was found between the groups (F: 30.17; p<0.001) (Table 6). The post-hoc test performed to determine the statistically significant difference arises from the difference between the two groups is given in Table 7. When these four groups were compared in terms of PCS scores, a significant difference was found between the groups (F: 23.50; $p<0.001$ ) (Table 6). The results of the post-hoc test for the relevant variance analysis are presented in Table 7.

\section{Discussion}

In some of the cases presenting with the complaint of acute low back pain, limiting straight leg raising (Lasegue sign) and lumbar MRI findings from sciatica stretching tests performed in physical examination do not correspond to the severity of the perceived pain. In our study, we had a significant proportion of patients who had negative Lasegue sign (62 people) and/or who did not have any pathology in lumbar MR imaging (24 people). In various studies, the positivity of Lasegue sign was found to be between $57-90 \%$ in patients with low

\begin{tabular}{|l|l|}
\hline \multicolumn{2}{|l|}{ Table 2. Clinical features of the cases } \\
\hline \multicolumn{2}{|l|}{$\mathbf{n}(\%)$} \\
\hline Physical examination finding & $62(36.9)$ \\
\hline Lasegue negative & $106(63.1)$ \\
\hline Lasegue positive & $24(14.3)$ \\
\hline MR findings & $59(35.1)$ \\
\hline No finding & $40(23.8)$ \\
\hline Bulging & $40(23.8)$ \\
\hline Protrusion & $5(3.0)$ \\
\hline Extrude & \multicolumn{2}{|l|}{} \\
\hline Sequester & $59(35.1)$ \\
\hline Depression & $46(27.4)$ \\
\hline Minimal & $48(28.6)$ \\
\hline Mild & $15(8.9)$ \\
\hline Moderate & $73(43.5)$ \\
\hline Severe & $39(23.2)$ \\
\hline Anxiety & $23(13.7)$ \\
\hline Low & $33(19.6)$ \\
\hline Mild & Mean \pm Standard deviation \\
\hline Moderate & $2.54 \pm 1.24$ \\
\hline Severe & \\
\hline Pain duration (week) & \\
\hline MR: Magnetic resonance & \\
\hline
\end{tabular}




\begin{tabular}{|c|c|c|c|c|c|c|}
\hline & & Pain duration & NPRS & PCS & BAI & BDI \\
\hline \multirow{2}{*}{ Pain duration } & $r$ & 1 & -0.142 & -0.015 & -0.149 & -0.132 \\
\hline & $p$ & - & 0.067 & 0.852 & 0.055 & 0.088 \\
\hline \multirow{2}{*}{ NPRS } & $r$ & -0.142 & 1 & $0.604^{* *}$ & $0.596^{* *}$ & $0.603^{* *}$ \\
\hline & $p$ & 0.067 & - & 0.000 & 0.000 & 0.000 \\
\hline \multirow{2}{*}{ PCS } & $r$ & -0.015 & $0.604^{* *}$ & 1 & $0.540 * *$ & $0.599 * *$ \\
\hline & $p$ & 0.852 & 0.000 & - & 0.000 & 0.000 \\
\hline \multirow{2}{*}{ BAI } & $r$ & -0.149 & $0.596^{* *}$ & 0.540 ** & 1 & $0.861^{\text {** }}$ \\
\hline & $p$ & 0.055 & 0.000 & 0.000 & - & 0.000 \\
\hline \multirow{2}{*}{$\mathrm{BDI}$} & $r$ & -0.132 & $0.603^{* *}$ & 0.599 ** & $0.861^{* *}$ & 1 \\
\hline & $p$ & 0.088 & 0.000 & 0.000 & 0.000 & - \\
\hline
\end{tabular}

\begin{tabular}{|c|c|c|c|c|c|c|}
\hline & & Sum of squares & df & Mean square & $F^{*}$ & $p$ \\
\hline \multirow{3}{*}{ NPRS } & Between groups & 187.452 & 3 & 62.484 & 26.466 & $<0.001$ \\
\hline & Within groups & 387.191 & 164 & 2.361 & - & - \\
\hline & Total & 574.643 & 167 & - & - & - \\
\hline \multirow{3}{*}{ PCS } & Between groups & 9684.575 & 3 & 3228.192 & 31.250 & $<0.001$ \\
\hline & Within groups & 16941.401 & 164 & 103.301 & - & - \\
\hline & Toplam & 26625.976 & 167 & - & - & - \\
\hline
\end{tabular}

Table 5. *Post-hoc analysis of depression groups in terms of pain severity and catastrophizing

\begin{tabular}{|c|c|c|c|c|c|}
\hline $\begin{array}{l}\text { Dependent } \\
\text { variable }\end{array}$ & Comparison groups for depression & Mean difference & $p$ & \multicolumn{2}{|c|}{$95 \%$ Confidence interval } \\
\hline & & & & Lower & Upper \\
\hline \multirow{5}{*}{ NPRS } & Minimal-low & $-1.05527^{*}$ & 0.003 & -1.8397 & -0.2708 \\
\hline & Minimal-moderate & $-2.27719^{*}$ & $<0.001$ & -3.0524 & -1.5020 \\
\hline & Minimal-severe & $-2.94802^{*}$ & $<0.001$ & -4.1013 & -1.7948 \\
\hline & Mild-moderate & $-1.22192^{*}$ & 0.001 & -2.0448 & -0.3990 \\
\hline & Mild severe & $-1.89275^{*}$ & $<0.001$ & -3.0786 & -0.7069 \\
\hline \multirow{5}{*}{ PCS } & Minimal-mild & $-14.54273^{*}$ & $<0.001$ & -19.6705 & -9.4149 \\
\hline & Minimal-severe & $-18.68023^{*}$ & $<0.001$ & -26.3086 & -11.0519 \\
\hline & Mild-moderate & $-14.53351^{*}$ & $<0.001$ & -19.9767 & -9.0904 \\
\hline & Mild-severe & $-18.67101^{*}$ & $<0.001$ & -26.5148 & -10.8272 \\
\hline & Moderate-severe & $-10.39526^{*}$ & 0.002 & -17.9074 & -2.8831 \\
\hline
\end{tabular}

*Tukey test, NPRS: Numerical rating scale for pain, PCS: Pain catastrophizing scale, statistical significance level: $p<0.008$, (Only statistically significant comparisons are presented)

back pain $(19,20)$. In our study, although the Lasegue test was found to be positive in 106 of 168 cases with low back pain complaints (63\%), in 62 of these cases, moderate and severe herniation findings (protrusion, extrusion and sequestration) were detected in radiology. This finding suggests that other factors besides pathology also contribute to the perception of pain severity. As a matter of fact, the psychosocial aspect of low back pain is emphasized as well as its biological aspect (21-23).
Since pain is a subjective symptom, various measurement tools have been developed for grading. NPRS is one of the tools used for pain grading and is used to assess pain in other pain types such as low back pain $(12,24)$ The positive correlation between pain severity and anxiety and depression levels is one of the important findings of our study. It has been shown that low back pain is associated with depression (25-27) and it has been stated that depression may have a negative effect on the 


\begin{tabular}{|c|c|c|c|c|c|c|}
\hline & & Sum of squares & df & Mean square & $F^{*}$ & $p$ \\
\hline \multirow{3}{*}{ NPRS } & Between groups & 204.375 & 3 & 68.125 & 30.174 & $<0.001$ \\
\hline & Within groups & 370.268 & 164 & 2.258 & - & - \\
\hline & Total & 574.643 & 167 & - & - & - \\
\hline \multirow{3}{*}{ PCS } & Between groups & 8006.936 & 3 & 2668.979 & 23.509 & $<0.001$ \\
\hline & Within groups & 18619.040 & 164 & 113.531 & - & - \\
\hline & Total & 26625.976 & 167 & - & - & - \\
\hline
\end{tabular}

Table 7. *Post-hoc analysis of anxiety groups in terms of pain severity and catastrophizing

\begin{tabular}{|c|c|c|c|c|c|}
\hline $\begin{array}{l}\text { Dependent } \\
\text { variable }\end{array}$ & Comparison groups for anxiety & Mean difference & p & \multicolumn{2}{|c|}{ \%95 Confidence interval } \\
\hline & & & & Lower & Upper \\
\hline \multirow{3}{*}{ NPRS } & Low-moderate & $-1.90232^{*}$ & $<0.001$ & -2.8349 & -0.9698 \\
\hline & Low-severe & $-2.83645^{*}$ & $<0.001$ & -3.6545 & -2.0184 \\
\hline & Mild- severe & $-2.02331^{*}$ & $<0.001$ & -2.9458 & -1.1009 \\
\hline \multirow{3}{*}{ PCS } & Low- severe & $-17.81694^{*}$ & $<0.001$ & -23.6182 & -12.0157 \\
\hline & Mild- severe & $-16.86014^{*}$ & $<0.001$ & -23.4015 & -10.3188 \\
\hline & Moderate- severe & $-10.39526^{\star}$ & 0.002 & -17.9074 & -2.8831 \\
\hline
\end{tabular}

prognosis of low back pain (28). In various studies, it has been shown that those with severe pain have more severe psychological distress $(29,30)$. The relationship between pain intensity and depression and anxiety is also observed in rheumatoid arthritis (31), headache (32), and gastrointestinal system disorders (33). Bener et al. (34) compared 1,290 low back pain patients with a control group of 890 people and found that anxiety and depression levels were higher in the low back pain group. It is understood that these findings are in parallel with the literature. On the other hand, in a twin study, it was suggested that the relationship between low back pain and depression may be due to familial genetic factors rather than causation (35).

In addition to the relationship between pain and depression and anxiety, disastrous pain is also of great importance in the perception of pain. It has been reported that disastrous pain is one of the psychological factors that cause the person to perceive the intensity of pain more than it really is. In a study conducted to evaluate these psychological factors, lower PCS scores were found in patients who received training before lumbar surgery (36). It has been shown that informing about the pain may cause a decrease in the PCS scores or may have a positive change in the radiological findings (37). It has also been shown that catastrophizing plays an important role in modulating postoperative pain in patients who have undergone spine surgery and used PCS (38). Disaster is actually used as a coping strategy. It has also been found that catastrophizing is associated with disability and delayed recovery as well as pain (39). In a study in which half of the participants were found to be highly catastrophic, it was found that disastrous pain was associated with more severe pain (40). In our study, higher NPRS scores were found in those with higher PCS scores.

\section{Study Limitations}

The absence of a control group in our study can be considered as a limitation. Determining the frequency of anxiety and depression symptoms in the control group without low back pain could have contributed to the study.

\section{Conclusion}

The study findings showed that there is a significant relationship between psychological and cognitive state and low back pain. Low back pain may also be one of the symptoms of somatization in depression, and some depressed patients may be admitted to the hospital with low back pain. Depression and anxiety can lower the pain threshold or, conversely, aggravate existing depression and anxiety. In addition, low back pain can lead to disability, as well as existing or developing anxiety and depression alone can lead to disability. Therefore, patients with low back pain should be handled in a detailed and versatile way and the treatment plan should be made in the light of this information.

\section{Authorship Contributions}

Concept: O.E.B., Design: O.E.B., Data Collection or Processing: B.O., Analysis or Interpretation: B.O., Literature Search: O.E.B., Writing: O.E.B., 
Conflict of Interest: No conflict of interest was declared by the authors.

Financial Disclosure: The authors declared that this study received no financial support.

\section{References}

1. Bonica-Loeser J. Low back pain. In: Loeser J, editor. Bonica's Manag Pain, Philadelphia: Lippincott Williams \& Wilkins; 2001. p. 1508-64.

2. Loney PL, Stratford PW. The prevalence of low back pain in adults: a methodological review of the literature. Phys Ther 1999;79:384-96.

3. Türkiye İstatistik Kurumu (TUIK). Bireylerin son 12 ay içerisinde yaşadığı başlıca hastalık/sağlık sorunlarının cinsiyete göre dağılımı 2016.

4. WHO (World Health Organization). Depression and Other Common Mental Disorders Global Health Estimates. 2017. p. 24.

5. Arango-Dávila CA, Rincón-Hoyos HG. Depressive Disorder, Anxiety Disorder and Chronic Pain: Multiple Manifestations of a Common Clinical and Pathophysiological Core. Rev Colomb Psiquiatr 2018;47:46-55.

6. Bansal D, Asrar M. Disability and depression in low back pain. Evidence from a cohort study. Value Heal 2020;23:226.

7. Eser $E$, Fidnner $H$, Fidaner C, Eser SY, Elbi H, Göker E. WHOQOL-100 ve WHOQOL-BREF'in psikometrik özellikleri. 3P Derg 1999;7:1-18.

8. Christe G, Crombez G, Edd S, Opsommer E, Jolles BM, Favre J. Relationship between psychological factors and spinal motor behaviour in low back pain: a systematic review and metaanalysis. Pain 2021;162:672-86.

9. Granot M, Ferber SG. The roles of pain catastrophizing and anxiety in the prediction of postoperative pain intensity: a prospective study. Clin J Pain 2005;21:439-45.

10. Fernandes L, Storheim K, Lochting I, Grotle M. Crosscultural adaptation and validation of the Norwegian pain catastrophizing scale in patients with low back pain. BMC Musculoskelet Disord 2012;13:111.

11. Sullivan MJL, Bishop SR, Pivik J. The Pain Catastrophizing Scale: Development and validation. Psychol Assess 1995;7:524-32.

12. Childs JD, Piva SR, Fritz JM. Responsiveness of the numeric pain rating scale in patients with low back pain. Spine (Phila Pa 1976) 2005;30:1331-4.

13. Beck AT, Steer RA, Carbin MG. Psychometric properties of the Beck Depression Inventory: Twenty-five years of evaluation. Clin Psychol Rev 1988;8:77-100.

14. Beck AT, Epstein N, Brown G, Steer RA. An inventory for measuring clinical anxiety: psychometric properties. J Consult Clin Psychol 1988;56:893-7.
15. Süren M, Okan I, Gökbakan AM, et al. Factors associated with the pain catastrophizing scale and validation in a sample of the Turkish population. Turk J Med Sci 2014;44:104-8.

16. Yap JC, Lau J, Chen PP, et al. Validation of the Chinese Pain Catastrophizing Scale (HK-PCS) in patients with chronic pain. Pain Med 2008;9:186-95.

17. Hisli N. Beck Depresyon Envanterinin üniversite öğrencileri için geçerliği , güvenilirliği. Psikol Derg 1989;7:3-13.

18. Ulusoy M, Sahin NH, Erkmen H. Turkish Version of the Beck Anxiety Inventory: Psychometric Properties. J Cogn Psychother 1998;12:163-72.

19. Falavigna A, Righesso O, Teles AR, Kleber FD, Canabarro CT, Da Silva PG. Is the Lasègue Sign a predictor of outcome in lumbar disc herniation surgery? Coluna/ Columna 2013;12:304-7.

20. Kosteljanetz M, Bang F, Schmidt-Olsen S. The clinical significance of straight-leg raising (Lasègue's sign) in the diagnosis of prolapsed lumbar disc. Interobserver variation and correlation with surgical finding. Spine (Phila Pa 1976) 1988; 13:393-5.

21. Waddell G. The Back Pain Revolution. 2nd ed. London: Churchhill Livingstone; 2004. p. 480.

22. Seward J, Stavrinos D, Moore D, Attridge N, Trost Z. When driving hurts: characterizing the experience and impact of driving with back pain. Scand J Pain 2021 Feb 23.

23. National Library of Medicine. Confinement Effect on Low Back Pain Intensity in Chronic Low Back Pain Patients (CONFILOMB) 2020.

24. Michener LA, Snyder AR, Leggin BG. Responsiveness of the numeric pain rating scale in patients with shoulder pain and the effect of surgical status. J Sport Rehabil 2011;20:115-28.

25. Robertson D, Kumbhare D, Nolet P, Srbely J, Newton G. Associations between low back pain and depression and somatization in a Canadian emerging adult population. J Can Chiropr Assoc 2017;61:96-105.

26. Unalan D, Celikten M, Mazicioğlu M. Depressive symptom profile of Turkish students experiencing back pain. Soc Behav Personal an Int J 2009;37:155-62.

27. Peker K, Polat R. The effects of preoperative reactions of emotional distress on headache and acute low back pain after spinal anesthesia: A prospective study. J Psychosom Res 2021;144:110416.

28. Pinheiro MB, Ferreira ML, Refshauge $K$, et al. Symptoms of depression as a prognostic factor for low back pain: a systematic review. Spine J 2016;16:105-16.

29. Selim AJ, Ren XS, Fincke G, et al. The importance of radiating leg pain in assessing health outcomes among patients with low back pain. Results from the Veterans Health Study. Spine (Phila Pa 1976) 1998;23:470-4.

30. BenDebba M, Torgerson WS, Long DM. A validated, practical classification procedure for many persistent low back pain patients. Pain 2000;87:89-97. 
31. Zyrianova Y, Kelly BD, Gallagher C, et al. Depression and anxiety in rheumatoid arthritis: the role of perceived social support. Ir J Med Sci 2006;175:32-6.

32. Zwart JA, Dyb G, Hagen K, et al. Depression and anxiety disorders associated with headache frequency. The NordTrøndelag Health Study. Eur J Neurol 2003;10:147-52.

33. Zvolensky M, Jardin C, Farris SG, et al. Gut interpretations: how difficulties in emotion regulation may help explain the relation of visceral sensitivity with depression and anxiety among young adults with gastrointestinal symptoms. Psychol Health Med 2018;23:840-5.

34. Bener A, Verjee M, Dafeeah EE, et al. Psychological factors: anxiety, depression, and somatization symptoms in low back pain patients. J Pain Res 2013;6:95-101.

35. Fernandez M, Colodro-Conde L, Hartvigsen J, et al. Chronic low back pain and the risk of depression or anxiety symptoms: insights from a longitudinal twin study. Spine J 2017; 17:90512.
36. Louw A, Diener I, Puentedura EJ. The short term effects of preoperative neuroscience education for lumbar radiculopathy: A case series. Int J Spine Surg 2015;9:11.

37. Louw A, Puentedura EJ, Diener I, Peoples RR. Preoperative therapeutic neuroscience education for lumbar radiculopathy: a single-case fMRI report. Physiother Theory Pract 2015;31:496-508.

38. Dunn LK, Durieux ME, Fernández LG, et al. Influence of catastrophizing, anxiety, and depression on in-hospital opioid consumption, pain, and quality of recovery after adult spine surgery. J Neurosurg Spine 2018;28:119-26.

39. Wertli MM, Eugster R, Held U, Steurer J, Kofmehl R, Weiser S. Catastrophizing-a prognostic factor for outcome in patients with low back pain: a systematic review. Spine J 2014;14:2639-57.

40. Ogunlana MO, Odole AC, Adejumo A, Odunaiya N. Catastrophising, pain, and disability in patients with nonspecific low back pain. Hong Kong Physiother J 2015;33:73-9. 